cell and colour filter gives the same results as the average eye is being investigated.

During the past year an entirely new section, on control mechanisms, has been added to the Metrology Division. This group has in hand the development of an electro-mechanical differential analyser. This machine will have twenty mechanical integrators and gear systems, interconnected by electrical remote control position servo-mechanisms, which will enable it to be used either as a whole or in sections permitting the simultaneous solving of several problems. A prototype model comprising two integrators was on view. The section is also concerned with the study of the principles of automatic control, and a pilot plant has been designed and constructed for this purpose. Oil is circulated through the plant and its temperature automatically controlled by closedcycle systems employing the proportional, the floating (or integral) or the first derivative (or rate) method of control. Alternative control methods will also be investigated.

Ternary alloys of iron, nickel and chromium form the basis of numerous commercial alloys for use at service temperatures between $500^{\circ}$ and $800^{\circ} \mathrm{C}$. It is desirable-in many cases essential - that exposure to these high temperatures should not bring about any micro-structural changes which might be accompanied by a deterioration in the mechanical properties of the alloys. One such possible change is the formation of the brittle sigma phase in alloys of certain compositions when heated within the $500^{\circ}-800^{\circ} \mathrm{C}$. range, and the composition and temperature ranges over which this phase is precipitated in pure iron-nickelchromium alloys is under investigation in the Metallurgy Division. One of several interesting points shown by this work is the extreme sluggishness of the process by which the sigma phase is formed in alloys containing about 20 per cent chromium, and the effect of increasing proportions of nickel on the sluggishness of the reaction. The indications are that alloys containing about 20 per cent of chromium and not less than 25 per cent of nickel will only attain true equilibrium after many months annealing at temperatures between $550^{\circ}$ and $650^{\circ} \mathrm{C}$.

Two new induction furnaces to be added to the equipment of the Division will be used in the first place to make alloys for studying the effects of alloying elements on the properties of pure iron. One furnace, designed to melt at least $50 \mathrm{lb}$. of iron in air, has already been installed, and a second furnace designed to melt $25 \mathrm{lb}$. of iron in vacuo is at present under construction.

The Ship Division, working in close collaboration with the principal shipbuilders and naval architects, is rendering very useful service in solving difficulties with regard to ship-form design, and models of all classes of ships, ranging from 30,000 -ton liners to 45-ton launches, are tested in one or other of the two tanks. As a result of such tests, corrections to improve performance are made in the ship and, in many cases, a final check is carried out by staff during an actual voyage. Various pieces of apparatus used in these full-scale tests at sea were on view, and hull-form tests and propulsion experiments were being carried out in the tanks.

Modern requirements as regards comfort in buildings coupled with the necessity for fuel economy have led to an intensive study of the properties of walls, roofs and floors as regards resistance to heat flow. The Physics Division of the Laboratory displayed a wide range of equipment of this nature for dealing with, say, wall-sections weighing half a ton or thin sheeting materials such as wall-boards. Work is also carried out on wall-sections of cavity construction when the external surface is subjected to a daily cycle of radiation simulating conditions in the tropics. The uniform stream of radiation is supplied by a battery of incandescent lamps run at low filamenttemperature and mounted in parabolic reflectors.

Since the War, fundamental work on acoustical measurement standards has been recommenced and the section concerned has been largely re-equipped. A new development on view this year was a large acoustic duct in which plane waves of sound are generated to serve for the standardization of microphones at low frequencies and for other experiments involving low-pitched sounds.

One of the sections of the Mathematics Division, that concerned with research into new computing methods and machines, is now engaged in the development of an automatic computing engine, the ACE, and a short lecture on electronic computing machines was given twice on each afternoon during the exhibition. A correlogram calculator constructed at the Laboratory was on view. This instrument is used for calculating serial correlation coefficients direct from a continuous graphical record, and uses three pairs of wheel and disk integrators linked together by an averaging motion.

\section{THE CHEMICAL RESEARCH LABORATORY, TEDDINGTON}

$\mathrm{R}$ EPRESENTATIVES of all elements of the chemical community and including many distinguished foreign men of science have recently visited the Chemical Research Laboratory of the Department of Scientific and Industrial Research. These 'open days' coincided with the centenary celebrations of the Chemical Society, and a large party of fellows of the Society visited the Laboratory on July 17.

The Laboratory, founded in 1925 to provide a centre for the fundamental chemical research carried out in the Department of Scientific and Industrial Research, stands in the same grounds as the National Physical Laboratory. If it has not yet achieved the wide fame of its older and larger sister, it has shown a sturdy growth during its short life and, with the ending of its war-work, is entering upon a period of vigorous activity.

Since the end of hostilities, the Laboratory has been modernized and re-equipped. A large prefabricated building has been erected during the past fow months and is in full use. The new building has been named after Stephen Hales, to commemorate this great experimental scientific worker who was, for more than fifty years, vicar of Teddington. Much of the existing building has been overhauled and modified to accommodate new techniques. These include microanalysis, high-efficiency fractional distillation, spectrography and many more. The existing facilities in such major fields as the corrosion of metals, highpressure reactions and plastics have been improved and extended.

The buildings contain sixty-five rooms of various sizes, of which eleven are specialist laboratories and three semi-scale laboratories. The Laboratory also has a drawing office, two workshops and a glassworking room manned by skilled staff who are engaged 
on the design, production and maintenance of the apparatus required in the various researches.

The programme of the Laboratory is undertaken on the advice of the Chemistry Research Board, the present chairman of which is Sir Norman Haworth. In addition to its own research programme, the Laboratory collaborates with other stations of the Department of Scientific and Industrial Research, including the National Physical Laboratory, the Fuel Research Station, the Forest Products Research Laboratory, etc., and carries out research for other Government departments. At present problems are under investigation for the Admiralty, the Ministry of Supply, the Board of Trade and the Agricultural Research Council.

The results of the Laboratory's researches are communicated to the Departments concerned, and to British chemical industry, as well as being published in the usual scientific journals. Special reports are also issued. General reviews have appeared for the period up to 1934 ; for 1934-37; and a review for the years $1938-46$ is in the press.

The Laboratory, which is under the direction of Prof. R. P. Linstead, is organised in five main sections : corrosion of metals; inorganic; coal tar; high polymers and plastics. Provision is also made for exploratory and special work. Some past achievements of the Laboratory and a brief outline of its present work follow.

Corrosion, and particularly the rusting of iron and steel, cause losses of many millions of pounds per annum. This is not only a question of expense but also involves depletion of a natural resource which is not being renewed. It is, therefore, fitting that study of corrosion of metal and its prevention should have an important place in the programme of a laboratory established for the general benefit.

The formation of surface films by metals is a wellknown phenomenon. The anodic oxidation of aluminium, discovered by this group of workers, involves a deliberate thickening of the film that forms naturally on this metal. A method of stripping films from metal, devised by Dr. U. R. Evans and improved at the Chemical Research Laboratory, has enabled the invisible films from metals such as stainless steel to be removed and analysed.

Corrosion of metals immersed in salt- or fresh-water is studied under static conditions, and when the samples are rotated at low and at high speeds. The rotor test devised at the Laboratory, although primarily designed for fundamental studies, found an immediate application on the outbreak of war in the evaluation of protective coatings for ships. Electrochemical methods now show great promise in de. termining the breakdown of paint films in immersed conditions. Atmospheric corrosion is especially important in relation to the present building programme, and attention is being given to the development of accelerated tests of painted surfaces. Some kinds of underground corrosion are due to the influence of bacteria. These micro-organisms are anaerobic and the damage occurs in clay or water-logged soil. The microbiological group of the Laboratory is at present concentrating on a study of these bacteria.

The experience gained in these researches on corrosion often enables the staff to assist in solving ad hoc problems by advice or investigation. Sometimes such work leads to useful discoveries. For example, war-work on anti-freeze materials led to the discovery of the remarkable inhibitive properties of sodium benzoate both in aqueous solution and when incorporated in wrapping materials.

Prior to the War, the Inorganic Section was investigating flue dusts and ashes as sources of semirare metals, but during the War special investigations were undertaken on behalf of the Ministry of Home Security. The successful outcome of one of these was the production of a fire foam agent from a cheap and indigenous source, as well as the provision of valuable fundamental information on the physical properties of foams. The possibility of making an entirely satisfactory carbon black from indigenous products was also demonstrated by this Section on a pilot-scale plant. Work on semi-rare metals has now been resumed on a broader basis. Some quantity of gallium metal and germanium halides have been prepared from indigenous material and are available for experimental work on possible useful applications.

Investigation of the composition of the tars produced by low-temperature carbonization of coal was started in 1925. The Coal Tar Section devised a scheme of separating groups of tar constituents by low-boiling solvents and dilute aqueous solutions avoiding the use of high temperatures. By this means comparative figures for tars from different sources were obtained and interesting products separated. One of these, a high-boiling tar-phenol fraction, proved very effective as a wetting agent in the mercerization of cotton, and was produced commercially as 'Shirlacrol'.

The Section is now concerned with the isolation and identification of tar constituents, using the most refined methods of separation and technique, such as high-efficiency fractionation combined with azeotropic distillation, of which a special study is being made. Allied to this is the determination of the physical and physico-chemical constants of pure coaltar products by the most accurate methods available. Another objective is to find new uses for tar constituents or derivatives. For example, acenaphthene has been dehydrogenated to acenaphthylene, which, on polymerization or co-polymerization with styrene, yields polymers having interesting and promising characteristics.

Research on synthetic resins was one of the original topics in the programme of the Laboratory, and an outstanding contribution was the discovery of the ion-exchange resins, which has led to the establish. ment of a new branch of the plastics industry and to a new industrial technique. During the War, work was directed to immediate requirements, notably of the Ministry of Aircraft Production, such as the production of light-weight material using expanded resins, laminated boards and synthetic adhesives.

The High Polymer and Plastics Section is now engaged in fundamental studies of the relationship between chemical structure and the physical and physico-chemical properties of high polymers and plastics. Among the subjects under investigation are the development of improved synthetic glues and a fundamental study of ion-exchange resins with the view of producing a material of increased capacity or utility.

Pioneer work on high-pressure reactions, in the years following the founding of the Laboratory, resulted in the construction of apparatus and the discovery of catalysts by which aliphatic alcohols were formed from carbon monoxide and hydrogen, and aliphatic acids from alcohols and carbon monoxide. The high-pressure equipment then designed 
and constructed has proved a useful asset in the prosecution of the Laboratory's researches, and has frequently been made use of by industrial firms and other organisations. Other subjects under investigation are the production of various useful chemicals by catalytic hydrogenation and amination. A study is elso being made of the preparation and polymerization of substances containing silicon. The Organic Intermediates Section also played a useful part in the development of the new synthetic fibre 'Terylene'.

Items of biological or agricultural interest which have been investigated in recent years or are still under investigation include the discovery of one drug of outstanding properties. This substance, 2 : 7-diamino-9-phenyl-10-methyl-phenanthridinium bromide, or C.R.L.1553, has been widely used against nagana, a trypanosome disease of cattle in Africa.

In order to make further use of Colonial products, research was carried out by the Microbiological Group of the Laboratory into the production of food yeast from molasses. Yeast production up to a pilot-plant stage was successfully achieved using a special strain of yeast, and the process is now in the course of fullscale production in Jamaica.

In collaboration with stations of the Agricultural Research Council, effective sheep dips and sprays containing D.D.T. have been formulated against blowflies and sheep ticks, and special tar-acid emulsions were developed as a substitute for sulphuric acid in the destruction of potato haulm. The future policy of the Laboratory will be to extend these fruitful fields of discovery, to broaden the range of techniques available and to make the work of the Laboratory of the maximum possible value to British industry and to the chemical community as a whole.

\section{NUTRITION IN NEWFOUNDLAND*}

\begin{abstract}
A STUDY of the history of Newfoundland should convince even the most hardened opponent of the need for Government planning. This island, a little larger than Ireland, a little smaller than England, has now some 320,000 inhabitants, mostly descendants of the original settlers who came from the British Isles. These settlers established themselves on the basis of one industry-cod-fishing-and sold their dry salt cod in many markets of the world. They bothered little about agriculture, and they soon depleted the stocks of game which once enriched the interior. This dependence on a single 'cash crop' meant that a bad year or a fall in the demand for their product not only spelt economic distress at the time but also resulted in a general downward trend from which the community was unable to extricate itself. In 1934 it was found necessary to suspend Dominion status.
\end{abstract}

As might be expected, this economic degradation showed in the health of the people : in a high infantile mortality-rate, in the number of still and premature births, in the incidence of tuberculosis, and in various clinical signs of malnutrition, including sporadic outbreaks of dry beriberi. In 1944 it was decided to copy the American plan of 'enriching' white flour with iron and some B-vitamins; but measures far more comprehensive than that are needed if Newfoundland's sickness is to be cured. Fortunately, there are now signs that this fact is recognized.

- Report on Nutrition in Newfoundland. By Dr. D. P. Cuthbertson. Pp. 87. (Dominions No. 4.) (London: H.M. Stationery Office, 1847.)
18. 6d. net.
The nutrition workers who carried out the "Medical Survey of Nutrition in Newfoundland" in August 1944 were not content merely to report their clinical findings, but also submitted to the Commissioner for Public Health and Welfare specific recommendations for dealing with the situation, and they advised the setting up of a Council of Nutrition, "to include senior members representative of all the Departments concerned in the promotion of better nutrition of the people of the country". These recommendations were accepted by the Department of Public Health and Welfare as being "sound and essentially capable of being implemented", and a year later Dr. D. P. Cuthbertson, of the Medical Research Council, visited the island to advise on "the ways and means of approaching the programme in the field".

His report reviews the evidence compiled by the various surveys that had been made and discusses in detail the pros and cons of different methods of implementing the recommendations. The arguments range over such problems' as 'enrichment' versus higher extraction rates for flour, 'uneconomic' local milk production versus imported processed milk, etc., and are therefore of interest to other territories besides Newfoundland.

From it all emerges, quite clearly, the fact that this programme for the attainment of good nutrition is going to make demands on agriculture, education, transport, industry and, not least, on the people themselves. Planning and direction are essential for, in Dr. Cuthbertson's own words, "Newfoundland -. cannot, as at present constituted, exist as a sound economic unit capable of improving its social services so that there is freedom from want and disease".

M. W. GranT

\section{QUANTUM ELECTRODYNAMICS}

THE subject of quantum electrodynamics is 1 extremely difficult, even for the case of a single electron. The usual method of solving the corre. sponding wave equation leads to divergent integrals. To avoid these, Prof. P. A. M. Dirac* uses the method of redundant variables. This does not abolish the difficulty, but presents it in a new form, which may be dealt with in two ways. The first of these needs only comparatively simple mathematics and is directly connected with an elegant general scheme, but unfortunately its wave functions apply only to a hypothetical world and so its physical interpretation is indirect. The second way has the advantage of a direct physical interpretation, but the mathematics is so complicated that it has not yet been solved even for what appears to be the simplest possible case. Both methods seem worth further study, failing the discovery of a third which would combine the advantages of both.

There is another fundamental problem in quantum electrodynamics. The classical theory disagrees with experiment, in that it allows a charged particle, in the absence of an ingoing field, to build up an acceleration and to radiate energy. This difficulty can be overcome in the classical theory by imposing the extra condition that the final acceleration must be zero. In quantum electrodynamies, the first of the new methods mentioned above does not seem to need any extra condition. On the other hand, the

" "Developments in Quantum Electrodynamics", Communications of the Dublin Institute for Advanced Studies A3, 1946. 